\title{
ANALISIS STUDI KELAYAKAN LABORATORIUM ILMU PENGETAHUAN ALAM DI SMPN 2 TEMPUREJO JEMBER
}

\author{
R. B. Amalatus*, R. N. Alifha, I. S. Ningsih, A. Hartono, M. Ikbal \\ Program Studi Tadris IPA Universitas Islam Negeri KH. Achmad Siddiq Jember, Jember, Indonesia \\ *Corresponding Author: retnobulan5@gmail.com
}

DOI: $10.35719 /$ vektor.v2i1.25

\begin{abstract}
Abstrak. SMPN 2 Tempurejo merupakan salah satu sekolah dengan daerah terpencil yang memiliki fasilitas penuh terhadap mata pelajaran IPA. IPA adalah salah satu mata pelajaran yang mempelajari tentang fenomena alam dengan berbagai bidang kajian di dalamnya. IPA sangat erat kaitannya dengan praktikum dan laboratorium. Tidak etis rasanya mempelajari IPA tanpa melakukan praktikum di laboratorium. Dengan adanya sebuah permasalahan mengenai ruangan laboratorium yang multifungsi, maka peneliti bertujuan untuk melakukan studi kelayakan laboratorium IPA di SMPN 2 Tempurejo. Metode yang digunakan yaitu metode deskriptif dengan instrumen wawancara kepada guru IPA di SMPN 2 Tempurejo. Hasil penelitian menunjukkan bahwa dengan ruangan yang multifungsi dapat menjalankan segala kegiatan laboratorium dengan semestinya, aman, dan tertib terhadap prosedur yang ada, serta dapat dikatakan layak dalam penggunaan laboratorium. Harapan ke depannya dari laboratorium yaitu dapat membantu proses dari pembelajaran di sekolah sehingga dapat memahamkan siswa melalui kegiatan praktikum, tidak hanya berdasarkan teori saja.
\end{abstract}

Kata Kunci: IPA, kelengkapan, laboratorium, praktikum, studi kelayakan

\begin{abstract}
SMPN 2 Tempurejo is one of the schools in remote areas that has full facilities for science subjects. Science is one of the subjects that study natural phenomena with various fields of study in it. Science is closely related to practicum and laboratory. It's unethical to study science without doing practical work in the laboratory. With a problem regarding a multifunctional laboratory room, the researchers aimed to conduct a feasibility study of the science laboratory at SMPN 2 Tempurejo. The method used is descriptive method with interview instruments to science teachers at SMPN 2 Tempurejo. The results of the study indicate that with a multifunctional room, all laboratory activities can be carried out properly, safely, and in an orderly manner according to existing procedures, and can be said to be feasible in laboratory use. The hope in the future from the laboratory is that it can help the process of learning at school so that students can understand through practical activities, not only based on theory.
\end{abstract}

Keywords: equipment, feasibility study, laboratory, natural science, practicum

\section{PENDAHULUAN}

Kondisi pembelajaran yang berorientasi pada teori-teori tanpa proses ilmiah akan berdampak pada kualitas pendidikan anak bangsa yang cerdas dan memiliki sikap ilmiah. Proses ilmiah pada dasarnya merupakan serangkaian proses untuk memecahkan permasalahan yang terjadi di lingkungan sekitar dan kehidupan sehari-hari (Meita, 2017).

Terkait dengan karakteristik pembelajaran IPA yang mengarahkan peserta didik memiliki pengalaman dan kemampuan dalam metode ilmiah maka proses ilmiah penting 
untuk dilakukan dalam proses pembelajaran IPA. Perkembangan pesat Ilmu Pengetahuan Alam (IPA) saat ini, tidak terlepas dari pendekatan dan metode ilmiah yang telah digunakan. Salah satu cara memberikan pemahaman materi IPA kepada siswa dengan metode ilmiah tersebut adalah melalui praktikum. Praktikum terlaksana dengan efektif jika dalam melaksanakan kegiatan berpraktikum di laboratorium didukung oleh kemampuan guru yang kompeten (Hofstein dan Naaman, 2007).

Laboratorium Ilmu Pengetahuan Alam (IPA) sekolah merupakan sebuah ruangan, lingkungan atau lembaga tempat peserta didik belajar serta mengadakan percobaan yang berhubungan dengan ilmu fisika, kimia dan biologi (Fatah, 2017). Persoalan yang paling umum yang terjadi di laboratorium adalah masalah kualitas pengelolaan laboratorium yang meliputi penggunaan dan pemeliharaan peralatan laboratorium serta bahan praktikum (Wiratma, 2014). Untuk menghasilkan proses belajar mengajar dan hasil belajar yang berkualitas, laboratorium harus melengkapi sarana dan prasarana yang diperlukan dan sesuai dengan standar laboratorium IPA (Putri \& Fatmawati, 2019).

Penelitian ini bertujuan untuk melakukan studi kelayakan laboratorium IPA di SMPN 2 Tempurejo. Untuk kelengkapan alat dan bahan pada SMPN 2 Tempurejo sudah terfasilitasi dan sudah sangat lengkap, bahkan data inventaris dari sarana dan prasarana juga tertera dengan begitu banyaknya jumlah alat dan bahan. Hanya saja dalam pelaksanaan kegiatan praktikum siswa kurang berhati-hati ketika menggunakan alat yang tersedia sehingga tidak sedikit siswa yang dapat memecahkan alat-alat pada saat membersihkan dan pada saat mencucinya.

Berdasarkan dari hasil wawancara dengan Kepala Laboratorium SMPN 2 Tempurejo, sumber dana dan operasional laboratorium diperoleh dari dana BOS (Bantuan Operasional Sekolah) dengan melalui prosedur pengajuan ke pemerintah.

Pengelolaan laboratorium pada saat ini telah dikelola oleh teknisi/laboran yang sesuai dengan pendidikannya (Asisten pendamping praktikum). Struktur organisasi laboratorium, lengkap. Akan tetapi masih belum ada pembenahan sehingga untuk banner/bagan yang terpampang tetap struktur organisasi periode tahun ajaran sebelumnya. Struktur organisasi laboratorium sudah semestinya harus ada dan dibuat karena dapat digunakan sebagai bukti autentik pengadministrasian.

Berdasarkan hasil wawancara dengan guru IPA, SOP yang dilakukan di laboratorium SMPN 2 Tempurejo adalah mengutamakan pelaksanaan yang aman dan tidak mempersulit siswa. Aman yang dimaksud dalam SOP yaitu tetap berjalan sesuai standar yang berlaku sebagai contoh bahan-bahan kimia yang terdapat di laboratorium diupayakan untuk digunakan sebaik mungkin tanpa terjadi kecelakaan dan menjaga keselamatan dari para praktikan.

Harapan yang dikemukakan oleh guru IPA, laboratorium yang ada di sekolah dapat membantu dalam proses pembelajaran karena materi yang disampaikan melalui kegiatan praktikum dapat membuat siswa lebih mengerti dan memahami daripada sekedar membaca dan memahami teori dari buku. Jadi, kemajuan siswa setelah melakukan kegiatan praktikum ini hasilnya sangat terlihat oleh guru IPA yang mengajar.

\section{METODE}

Metode pendekatan yang digunakan dalam penelitian jurnal ini yaitu metode pendekatan deskriptif kualitatif dengan teknik pengumpulan data melalui wawancara. Metode deskriptif analisis adalah sebuah metode penelitian yang dapat menjawab pertanyaan-pertanyaan yang berkaitan dengan penelitian tertentu untuk memperoleh informasi-informasi yang diinginkan peneliti (Ismail Nurdin, 2019). Sedangkan teknik 
pengumpulan data wawancara adalah suatu proses interaksi yang dilakukan secara langsung antara pewawancara dengan narasumber atau responden (Anggraeni, 2001). Teknik ini dilakukan dengan terjun langsung ke SMPN 2 Tempurejo yang bertempat di desa Sanenrejo, Tempurejo, Jember. Narasumber atau responden yang dituju adalah guru dari mata pelajaran IPA. Beliau bernama Yuliana Candra Setiawan yang mengampu 12 kelas sekaligus sehingga dapat mengetahui keseluruhan informasi yang dibutuhkan oleh penelit

\section{HASIL DAN PEMBAHASAN}

\section{Kelengkapan Alat Dan Bahan}

Kelengkapan alat dan bahan adalah suatu hal yang sangat penting bagi jalannya kegiatan praktikum. Jika tidak ada alat dan bahan yang lengkap atau sesuai dengan materi yang dipelajari, maka kegiatan praktikum tidak akan berjalan dengan lancar. Alat dan bahan dalam laboratorium IPA tidak serta merta diletakkan begitu saja, tetapi alat dan bahan juga harus tertata rapi di sebuah lemari khusus agar perawatannya mudah dilakukan. Penyimpanan alat dan bahan dari setiap bidang kajian IPA harus dibedakan, misalnya alat dan bahan kimia sendiri, alat dan bahan fisika sendiri, serta alat dan bahan biologi sendiri.
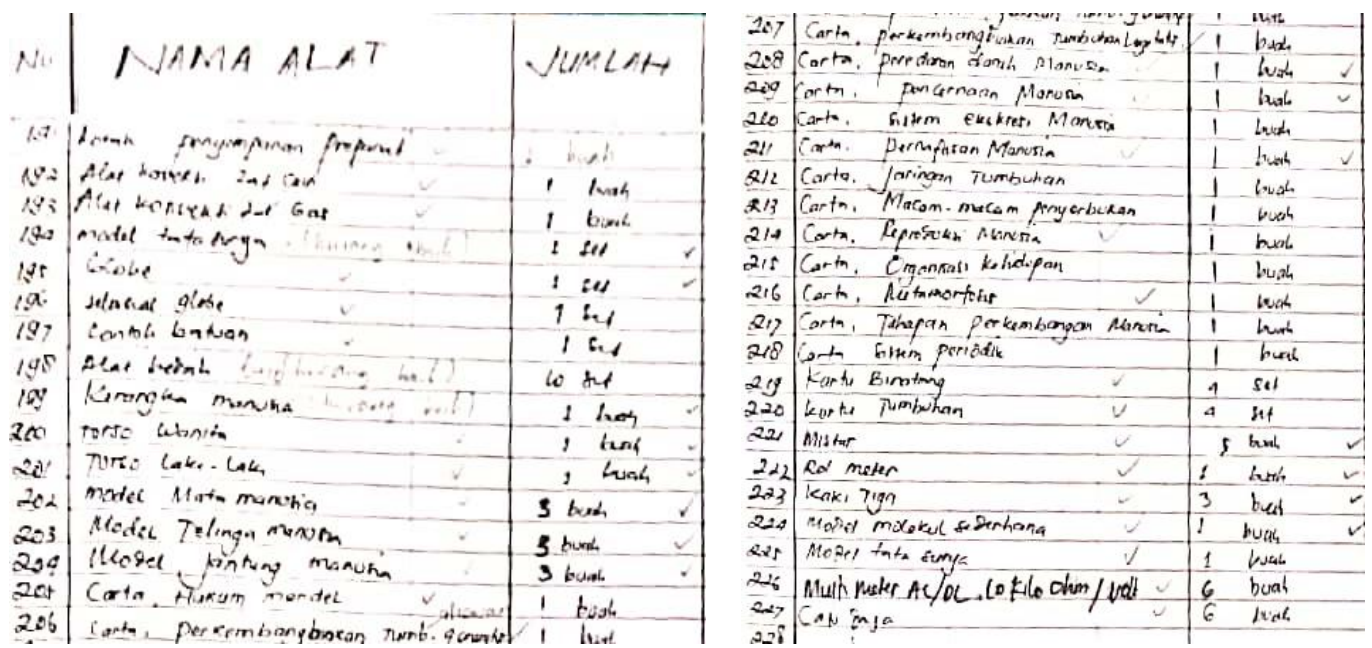

Gambar 1. Data Inventaris Alat dan Bahan Lab IPA SMPN 2 Tempurejo

Berdasarkan data inventaris pada gambar di atas, dapat dijelaskan bahwa kelengkapan alat dan bahan pada SMPN 2 Tempurejo sudah terfasilitasi dan sudah sangat lengkap, bahkan data inventaris dari sarana dan prasarana juga tertera dengan begitu banyaknya jumlah alat dan bahan. Hanya saja dalam pelaksanaan kegiatan praktikum siswa kurang berhati-hati ketika menggunakan alat yang tersedia sehingga tidak sedikit siswa yang dapat memecahkan alat-alat pada saat membersihkan dan mencuci, salah satunya yaitu tempered glass. Dari adanya kerusakan alat-alat yang ada di laboratorium tersebut, pihak sekolah masih belum bisa melakukan pengadaan ulang. Jika diharuskan untuk mengganti alat dan bahan sederhana yang dibawa dari rumah masing-masing, maka akan diupayakan oleh guru dengan kepemilikan fungsi yang sama dengan alat yang ada di laboratorium. Kalaupun memang tidak bisa dilakukan, maka 
siswa melakukan kegiatan praktikum dengan alat yang ada saja di laboratorium, serta mencari informasi atau literasi yang lain dari internet, youtube, dan lain sebagainya.

Sedangkan untuk penggunaan alat penting di laboratorium seperti mikroskop yang jumlahnya terbatas, maka siswa diarahkan untuk membentuk kelompok sesuai dengan ketersediaan alat yang ada di laboratorium dikarenakan semua siswa tidak memungkinkan untuk menggunakan mikroskop satu per satu. Dan untuk kelengkapan dari penggunaan jas laboratorium sendiri, di SMPN 2 Tempurejo ini masih belum dipergunakan karena dana dari pemerintah masih belum tercukupi untuk penanganan jas laboratorium tersebut. Untuk ke depannya, guru mengharapkan untuk melakukan penanganan mengenai jas laboratorium yang akan diajukan kepada kepala sekolah dan disampaikan ke pemerintah.

\section{Sumber Dana Dan Operasionalnya}

Sumber dana merupakan sebuah alat dalam menganalisa keuangan yang digunakan untuk mengetahui dana yang didapatkan berasal dari mana dan digunakan untuk apa. Sumber dana dalam pendidikan terpusat pada pemerintah. Pemerintah memegang kekuasaan tertinggi dalam hal pendanaan untuk memfasilitasi pelayanan pemerintah. Berdasarkan dari hasil wawancara dengan Kepala Laboratorium SMPN 2 Tempurejo, sumber dana dan operasional laboratorium diperoleh dari dana BOS (Bantuan Operasional Sekolah) dengan melalui prosedur pengajuan ke pemerintah. Apabila terdapat alat atau bahan praktikum yang kurang, maka hal tersebut tetap diajukan sesuai prosedur ke pemerintah.

\section{Struktur Organisasi Laboratorium}

Struktur organisasi laboratorium, Menurut Terry pengorganisasian merupakan kegiatan dasar manajemen. Pengorganisasian dilakukan untuk menghimpun dan menyusun semua sumber daya manusia sedemikian rupa, sehingga kegiatan pencapaian tujuan yang telah ditetapkan dapat dilaksanakan secara efektif dan efesien. Tujuan utama pengorganisasian adalah membantu orang-orang bekerja sama secara efektif dalam wadah organisasi atau lembaga. Menurut Torang, organisasi adalah entitas sosial yang terkoordinasi secara sadar, terdiri dari dua orang atau lebih dengan batasan yang relative teridentifikasi yang berfungsi secara berkelanjutan untuk mencapai seperangkat sasaran bersama (Dasar, 2007).

Menurut Sudaryanto, organisasi laboratorium adalah suatu sistem kerja sama dari sekelompok orang, barang, atau unit tertentu tentang laboratorium untuk mencapai tujuan yang telah ditetapkan. Dalam struktur organisasi laboratorium diperlukan pengelolaan yang lengkap dan baik, agar terjadi kesinambungan daya guna laboratorium dapat dipertahankan. Pengelola atau personil laboratorium mempunyai tanggung jawab terhadap efektifitas dan efesiensi laboratorium termasuk fasilitas, alat-alat, dan bahanbahan praktikum. Pada sekolah menengah biasanya laboratorium dikelola oleh seorang koordinator laboratorium yang diangkat dari guru (Fisika, Kimia, dan Biologi).

Berdasarkan dari hasil wawancara dengan Kepala Laboratorium SMPN 2 Tempurejo, Ibu Yuliana Candra Setiawan, beliau mengungkapkan; Pengelolaan laboratorium pada saat ini telah dikelola oleh teknisi/laboran yang sesuai dengan pendidikannya (asisten pendamping praktikum). Struktur organisasi laboratorium, lengkap. Akan tetapi masih belum ada pembenahan sehingga untuk banner/bagan yang terpampang tetap struktur organisasi periode tahun ajaran sebelumnya. Struktur organisasi laboratorium sudah semestinya harus ada dan dibuat karena dapat digunakan sebagai bukti autentik pengadministrasian. Terdapat struktur organisasi lengkap dalam pengelolaan laboratorium IPA di SMPN 2 Tempurejo, sebagaimana bagan dibawah ini: 


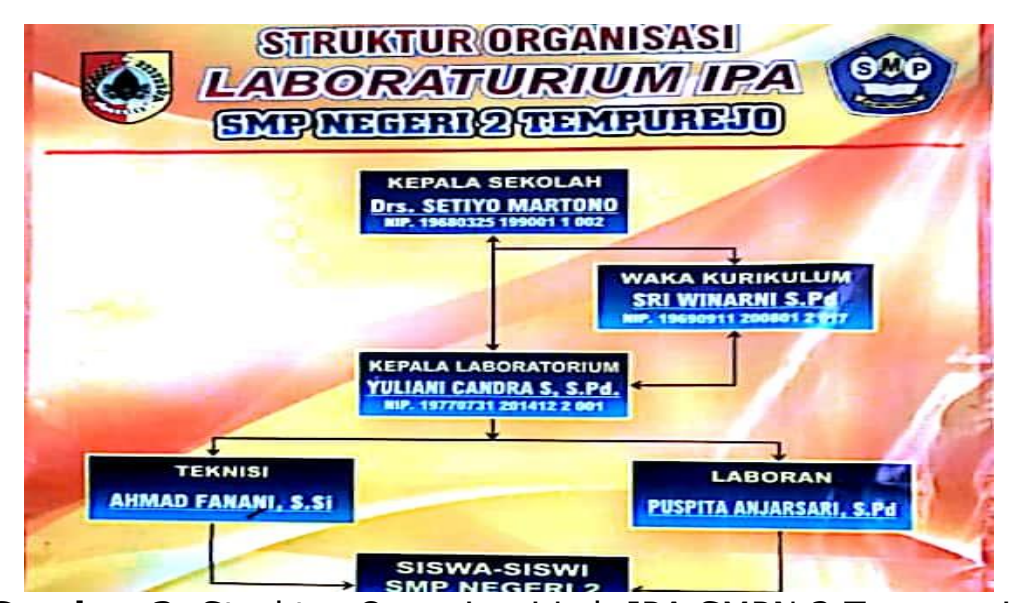

Gambar 2. Struktur Organisasi Lab IPA SMPN 2 Tempurejo

Berdasarkan Peraturan Pemerintah Nomor 19 Tahun 2005 Tentang Standar Nasional Pendidikan, tenaga laboratorium merupakan tenaga kependidikan pada SMP/MTs, SMA/MA, SMK/MAK, SDLB, SMPLB, SMALB atau bentuk lain yang sederajat. Struktur organisasi laboratorium sekolah/madrasah terdiri dari kepala sekolah/madrasah, kepala laboratorium, teknisi dan laboran.

Sesuai dengan bagan diatas, terdapat beberapa tenaga bantu di Laboratorium diantaranya:

a. Kepala Sekolah/Madrasah

Kepala sekolah/madrasah sebagai pilar tertinggi dalam struktur laboratorium. Kepala sekolah memiliki peranan diantaranya: 1). Memberi tugas Waka Sarana sebagai pembantu kepala madrasah untuk menangani sarana prasarana laboratorium; 2). Memberikan bimbingan, motivasi, pemantauan, dan evaluasi kepada petugas laboratorium; 3). Memberikan motivasi kepada para guru terutama guru IPA; 4). Menyediakan dana keperluan operasional laboratorium.

b. Waka Kurikulum dan Waka Sarana Prasarana

Waka Kurikulum berperan sebagai pembantu kepala sekolah/madrasah berkaitan dengan kesesuaian kurikulum, sedangkan Waka Sarana Prasarana berperan sebagai pembantu kepala sekolah/madrasah berkaitan dengan ketersediaan alat dan bahan laboratorium.

c. Kepala Laboratorium

Kepala Laboratorium bertugas melakukan pengelolaan khusus dengan mengkoordinasikan pembuatan struktur organisasi, penyusunan tata tertib laboratorium, dan menyusun jadwal kegiatan praktikum.

d. Teknisi Laboratorium

Teknisi laboratorium bertugas membantu kepala laboratorium dalam mempersiapkan alat dan bahan praktikum, serta pemeliharaan alat dan bahan tersebut. e. Asisten Laboratorium/Laboran

Laboran merupakan tenaga laboratorium yang membantu kepala laboratorium dalam mengelola bahan-bahan dan peralatan, serta melayani kegiatan praktikum (Salabi, 2016).

\section{SOP (Standart Operasional Prosedure) Laboratorium}

SOP laboratorium adalah sebuah acuan yang menjadi standar dalam menjaga kualitas, integritas dan kosistensi dari pemeriksaan-pemeriksaan yang dilakukan di Retno Bulan, dkk : Analisis Studi Kelayakan Laboratorium Ilmu Pengetahuan Alam......|53 
laboratorium. Keberadaan SOP dalam laboratorium merupakan syarat utama untuk memenuhi kriteria GLP (Good Laboratory Practice) sesuai dengan perundang-undangan yang berlaku di laboratorium (Laboratorium et al., 2020). SOP diberlakukan untuk menjaga keselamatan dari praktikan.

Berdasarkan hasil wawancara dengan guru IPA, SOP yang dilakukan di laboratorium SMPN 2 Tempurejo adalah mengutamakan pelaksanaan yang aman dan tidak mempersulit siswa. Aman yang dimaksud dalam SOP yaitu tetap berjalan sesuai standar yang berlaku sebagai contoh bahan-bahan kimia yang terdapat di laboratorium diupayakan untuk digunakan sebaik mungkin tanpa terjadi kecelakaan dan menjaga keselamatan dari para praktikan.

\section{Harapan Guru}

Harapan yang dikemukakan oleh guru IPA, laboratorium yang ada di sekolah dapat membantu dalam proses pembelajaran karena materi yang disampaikan melalui kegiatan praktikum dapat membuat siswa lebih mengerti dan memahami daripada sekedar membaca dan memahami teori dari buku. Jadi, kemajuan siswa setelah melakukan kegiatan praktikum ini hasilnya sangat terlihat oleh guru IPA yang mengajar.

\section{KESIMPULAN}

Setelah melakukan analisis dan wawancara kepada guru IPA di SMPN 2 Tempurejo mengenai studi kelayakan laboratorium, maka dapat disimpulkan bahwa dengan adanya suatu permasalahan tentang ruangan laboratorium yang multifungsi tidak menjadikan kegiatan laboratorium terhambat, melainkan tetap berjalan sebagaimana mestinya. Hasil studi kelayakan mengenai kelengkapan alat dan bahan laboratorium, sumber dana dan operasional laboratorium, struktur laboratorium, dan SOP (Standar Operasional Prosedur) pada laboratorium semuanya juga berjalan dengan semestinya, aman, dan tertib sesuai dengan prosedur yang ada, serta dapat dikatakan layak dalam penggunaannya. Untuk ke depannya, laboratorium diharapkan dapat membantu proses dari pembelajaran di sekolah sehingga dapat memahamkan siswa melalui kegiatan praktikum, tidak hanya berdasarkan teori saja.

\section{UCAPAN TERIMAKASIH}

Penulis mengucapkan terima kasih kepada dosen yang telah membimbing dan guru mata pelajaran IPA di sekolah, serta semua pihak yang membantu dan mendukung penelitian ini di SMPN 2 Tempurejo sehingga penelitian ini dapat dituangkan dalam bentuk tulisan yang dapat bermanfaat bagi dunia pendidikan.

\section{DAFTAR PUSTAKA}

Anggraeni, E. B. (2001). PENGANTAR EPIDEMIOLOGI EDISI 2. Jakarta: PENERBIT BUKU KEDOKTERAN EGC.

Dasar, P. (2007). Manajemen laboratorium. 1-15.

54| VEKTOR: Jurnal Pendidikan IPA, Vol. 02, No. 01, hlm. 49-55, 2021 
Fatah, Z. (2017). Sistem Informasi Laboratorium Ipa Di Man Bodowoso Menggunakan Php Dan Mysql, 3(2), 74-81.

Fatta, H. A. (2007). Analisis dan Perancangan Sistem Informasi untuk Keunggulan Bersaing Perusahaan dan Organisasi MOdern. Yogyakarta: ANDI.

Hofstein, A dan R.M. Naaman. (2007). The laboratory in science education: the state of the art. Journal the Royal Society of Chemistry, 8. (2), 105-107

Ismail Nurdin, S. H. (2019). METODOLOGI PENELITIAN SOSIAL. Surabaya: Media Sahabat Cendekia.

Laboratorium, D., Yogyakarta, P., Sugiharto, A. D., Sutanto, A., \& Hidayat, A. C. (2020). Analisis Patient Safety. 5(1), 24-36.

Meita, N. M. (2017). Studi Kelayakan Pengelola Laboratorium IPA SMP N 4 Sumenep. Pendidikan IPA, 7, 40-47.

Putri, D. P., \& Fatmawati, A. (2019). Sistem Informasi Pengelolaan Laboratorium IPA di SMP Negeri 1 Manggar. Jurnal INSYPRO (Information System and Processing), 4(2), $1-8$.

Salabi, A. (2016). Needs Assessment Laboratorium Biologi Pada Madrasah Aliyah Negeri (Man) Di Kota Banjarmasin. Jurnal PTK \& Pendidikan, 2(2), 27-34.

Wiratma, I. G. L., \& Subagia, I. W. (2014). Pengelolaan Laboratorium Kimia pada SMA Negeri di Kota Singaraja : ( Acuan Pengembangan Model Panduan Pengelolaan Laboratorium Kimia Berbasis Kearifan Lokal Tri Sakti ). Science Education, 3(2), 425-436. 